\title{
In Search of the Encounter between Religion and Mathematics
}

\author{
Wiwit Kurniawan ${ }^{1}$, Tri Hidayati ${ }^{2 *}$ \\ ${ }^{12}$ Pamulang University, Tangerang, Banten \\ *Corresponding author: ${ }^{1}$ wiwitkurniawan@unpam.ac.id, ${ }^{2}$ tribidayati@unpam.ac.id
}

\begin{abstract}
Religion and mathematics are perceived as two things that are very reciprocally exclusive; this is due to the opinion asserting that mathematics is considered as valid and objective knowledge. On the other hand, religion is something interpretive and subjective. Historically speaking, religion and mathematics have a strong association and in certain aspects, both of them have points of contact that can permeate each other. The forms of intersection between mathematics and religion need to be analyzed so that we will be able to see more clearly the current religious phenomenon. This study investigates and discovers a potential encounter between religion and mathematics. To see the relationship between religion and mathematics, and even their fusion, the first thing to do is determine the definition of religion and mathematics. With a clear understanding of both, the encounter points will be easier to recognize. The research method used in this study is a literature review. This study collects systematically a variety of literature related to the theme under study. The encounter between religion and mathematics undergoes at five dimensions, they are ontological, epistemological, teleological, theoretical and application dimension. This study more focused on similarities to reveal the connection between religion and mathematics.
\end{abstract}

Keywords: Encounter Point; Mathematics; Religion

\section{Introduction}

Religion and mathematics are perceived as two things that are very mutually exclusive $^{1}$ this is due to the opinion asserting that mathematics is considered

1 Javier Leach, Mathematics and Religion: Our Languages of Sign and Symbol (Templeton Press, 2010). 
as valid and objective knowledge. ${ }^{2}$ On the other hand, religion is something interpretive and subjective. Mathematics is regarded as the queen and servant of various scientific disciplines. Moreover, there is a sight that mathematics is a science that is universal, objective, and value-free. And, religion is believed to be subjective with value-loaded and undeniable truths that cannot be questioned. These two opposing characteristics considerably pervade our society and make people look as if both of them were contradicting. The irreconcilable characteristics inherent in mathematics and religion that are believed by society are not entirely true. There is a blurry line between the two.

Historically speaking, religion and mathematics have a strong association and in certain aspects, both of them have points of contact that can permeate each other. ${ }^{34}$ Many religious traditions in the past were closely related to mathematical activity. In the modern world, generally, mathematics may not enter the theological system of religion as in the classical and medieval eras, but its usefulness makes mathematics still very firmly linked to religion. In the tradition of Abrahamic religions, various rituals are highly dependent on timing that is based on mathematical knowledge of astronomy. Nowadays situation which is the power of religion has re-emerged; mathematics has a new meaning for a religious believer who is also an educated person. The forms of intersection between mathematics and religion need to be analyzed so that we will be able to see more clearly the current religious phenomenon.

This study investigates and discovers a potential encounter between religion and mathematics. The description of this study stretches from various theories concerning the relationship between religion and mathematics from various existing theories. In this effort, the writer has analyzed how the forms of the liaison of mathematics and religion, both in the dimensions of the object (mathematics and religion) and also the dimensions of the subject (religious person and mathematicians).

To see the relationship between religion and mathematics, and even their fusion, the first thing to do is determine the definition of religion and mathematics. With a clear understanding of both, the encounter points will be

2 Sarah Voss, "Mathematics and Theology: A Stroll through the Garden of Mathaphors," Theology and Science 4, no. 1 (January 2006): 33-49, https://doi.org/10.1080/14746700500501841.

3 Keith Devlin, Mathematics: The Science of Patterns: The Search for Order in Life, Mind and the Universe (Henry Holt and Company, 1996).

4 Andrew Gregory, "The Pythagoreans: Number and Numerology," Mathematicians and Their Gods: Interactions between Mathematics and Religious Beliefs. Oxford, UK, 2015. 
easier to recognize. The definition of both will not only clarify the line between them but also clarify the identity of their entities. In other words, the definition will provide a view of how the two entities can interact.

The hard thing that we have to accept is that it is impossible to briefly explain the perfect definition of religion because it has been related to the long-ranging traditions of human humankind. Therefore, a definition, no matter how good it is, will never cover all meanings of religion. Hence, the definition of religion in this study only emphasizes the pragmatic side which is useful for explaining its relationship with mathematics.

In a succinct definition, religion is considered as something related to the highest reality. ${ }^{5}$ Religion is an effort to search for the ultimate reality, highest truth, sacredness, deity, the forces that control nature, and understanding of whole reality. Religion in this sense seeks the meaning of life, the value of truth, and the meaning of the world. Religion explains the great things that arise

In simple terms, mathematics is an activity that deals with numbers. ${ }^{6}$ However, as with religion, there is no final definition of mathematics agreed upon by all experts. Since ancient times until the emergence of the world's great civilizations, mathematics has contributed to life. $^{7}$ We believe that the advancement of human civilization today owes much to mathematics. ${ }^{8}$ Although it looks pragmatic, in the past mathematics had often been associated with transcendental reality. ${ }^{9}$ Like the Pythagoreans and Platonists, mathematics was seen as something that represents the ultimate reality. ${ }^{1011}$ Therefore, sometimes mathematics is understood as an attempt to understand the ultimate reality.

In the view of the history of mathematics, religion and spirituality are very closely related to mathematics, especially in the ancient Greek era such as the Pythagorean and Platonist. Mathematics is perceived to have a mystical and spiritual dimension and it is considered as a pathway to the ultimate reality. ${ }^{12}$

In the modern era, mathematics has been secularized. As a result, the spiritual dimension is starting to disappear. Several recent studies about this

5 L. Bouckaert and L. Zsolnai, The Palgrave Handbook of Spirituality and Business (Springer, 2011).

6 Devlin, Mathematics.

7 Carl B. Boyer and Uta C. Merzbach, A History of Mathematics (John Wiley \& Sons, 2011).

8 Yuval Noah Harari, Sapiens: A Brief History of Humankind (Vintage, 2019).

9 Teun Koetsier and Luc Bergmans, Mathematics and the Divine: A Historical Study (Elsevier, 2004).

10 Gregory, "The Pythagoreans."

11 Philip Sidney Horky, Plato and Pythagoreanism (Oxford University Press, 2013).

12 Gregory, "The Pythagoreans." 
theme explore that the connection between mathematics and religion, especially spirituality, lies in the realm of individual activity and experience. The notion of sacred numbers and spiritual mathematics began to recede. The spiritual dimension that deals with mathematics does not correlate with mathematics itself, but in the activities of undergoing a mathematical process. It can be said that mathematics, the numbers, and theorems in them are not sacred, but the process of doing mathematics as an idealization and discovering the beauty of its patterns is a spiritual one.

Understanding of theo-mathematics or spiritual mathematics and perhaps further about mystical mathematics may be suitable for mathematics in the past. Mathematics in the modern era has undergone extraordinary transformations and developments. Therefore, we also need to explore how mathematics in this secular world still leaves its sanctity. Is the concept of spiritual mathematics still relevant?

In the spiritual mathematics paradigm, the link between mathematics and religion appears; however, because it is at the level of mathematical process and experience, religion is subjective. Therefore, we need to further explore other dimensions in which the linkage between mathematics and religion is possible, such as in the ontological dimension of both.

Because of the processes of secularization and modernization, forms of religiosity and spirituality are excluded from mathematics. In this situation, the consolidation of mathematics and religion was only possible on the external side. It is considered that they cannot meet in the realm of theory and epistemology. There is no mathematical theorem that is religious, simply like that. In the dimension of the subject (mathematician and religious person) is where the connection of them emerges. Some thinkers view the encounter of religion and mathematics as only occurring in the realm of mathematics education or the experience side of mathematics users or learners.

This notion is not absolutely true because in the internal dimension of mathematics and religion exist resemblances which allow them to interact, as happened in the classical era. This study enclosures a comprehensive point of view that embraces the whole aspect for pursuing possible connection of mathematics and religion.

This research is important because it will explore possible encounters outside these boundaries. It will explore mathematical encounters in various domains, especially possibilities in the internal realm. This study will look for 
various meeting points and encounters between religion and mathematics. The study of this encounter is not only in the realm of individual subjective opinion or interpretation of the spiritual process of mathematical activities. This study opens up new possibilities for encounters between religion and mathematics in various fields.

The purpose of this study is to reveal where and how the meeting between religion and mathematics by looking at various possible encounters, both in the domain of the object and the subject/user. From the background revealed, the problem formulation in this study is what and how is the possibility of the encounter between religion and mathematics, either in the subject domain (external) or in the object domain (internal).

Throughout human history, mathematics has had a strong and correlated nexus. Mathematics, whether it is a separate entity or an entity that is included in the theological system of religion, will always influence and shape religious images. By looking at how the two are related, it will be easier to understand the new phenomenon of religion.

\section{Literature Review}

\subsection{Theories about religion and mathematics connection}

Religion and mathematics indeed have considerable differences, yet it does not make them separated completely. Historically, the intersection between mathematics and religion seems to be vague because they have similar objectives namely to reveal the ultimate reality. The ancient version of mathematics is certainly different from nowadays. Certain rituals and some religious activities utilized mathematics as a medium of rites and to some extent, it was a part of religious doctrines.

In the modern and secular world, mathematics has developed and evolved in a much more complex and mundane form, but it does not mean mathematics is void of spiritual meaning and interaction with something sacred. The activities of mathematics for certain people are considered as a spiritual experience. Kessler provided four possible gateways where the mathematician is able to experience spirituality while doing the mathematics process. He mentioned that Pragmatic Platonism, Aesthetics, The study of patterns, and Inner vision are gateways for mathematics to encounter spirituality. ${ }^{13}$ Briefly, these gateways

13 Volker Kessler, "Spirituality in Mathematics," Journal for the Study of Spirituality 9, no. 1 (2019): 51. 
provide the prospect for mathematics to encounter religiosity. Kessler's gateways for mathematics to encounter spirituality excessively depend on the subjects who do mathematics. So, it may possible for certain people not to experience spirituality while doing mathematics because those people do not have the required interpretation about mathematics that enables several mathematical characteristics can be perceived as spirituality. For instance, elementary students may do not experience spirituality when they learn math because they have no spiritual interpretation of the mathematical activity they undergo. Based on this, it is assumed that Kessler's gateways are subjective and dependent on personal interpretation. This encounter happens in the external dimension of mathematics and religion.

The other version of Kessler' notion about the field or domain of encounter has been provided by Stenmark. He gave the opinion that religion and science can encounter at several dimensions, namely social dimension, teleology dimension, epistemological dimension, and theory dimension. ${ }^{14}$ Those dimensions are fields where science possibly encounters religion. Even though Stenmark discussed science, it is possible to regard science as commensurable with mathematics in this case. Hence, $\mathrm{He}$ has delivered an obvious and expanding comprehension about the encounter of religion and mathematics which is not constrained in an external domain or the practitioner interpretation but it is possible to mingle religion and mathematics in the internal domain of them such as epistemology, teleology, and theory. Stenmark seems still believes that there is a spirituality that is inherent in mathematics itself. It gives a hint that there is an internal domain of mathematics and religion where they encounter and intertwine each other. This paradigm encloses the limitation and encourages exploring and probing new encounter points between them.

As Karel Stenmark had described about the possibility of integration between science and religion, this study also uses the model from the Stenmark as a map to trace the interrelationships between religion and mathematics, of course, with the necessary modifications and developments. The linkage can be seen from the object dimensions (religion and mathematics) which are both at the scientific and philosophical levels meet to form related scientific discourses. Linkages can also appear on the subject or user (mathematician and religious person) dimension. The encounter is not in the internal field of mathematics or

14 Mikael Stenmark, How to Relate Science and Religion: A Multidimensional Model (Wm. B. Eerdmans Publishing, 2004). 
religious studies, but the realism of people who use it. In internal discourse, it may be that mathematics and science are not interrelated vividly, but someone who works with both has their interpretation of these two objects. The subjective interpretation of this person can be captured as an encounter, although the object (internal dimension of mathematics and religion) does not make any contact.

\subsection{Finding the Meaning of Religion}

In order to detect delicate spiritual entities in such a mathematics form and activities, redefining the meaning of religion is significantly necessary. Religion must be perceived in a general definition to detect infinitesimal religious entities. Taylor described that religion is the faith or belief relating to spiritual and ultimate reality. This is in accordance with Bolt's definition that "religion is an organized approach to the supernatural reality through human activities, which are mostly spiritual and usually encompass a set of narratives, beliefs, and practices". ${ }^{15}$ This general and vast definition is important because it allows us to take into account the elementary form of religiosity. If religion were comprehended as a sacred system of law and manifested in institution form, religious form in mathematics would not be noticeable vividly. Smith has investigated that the concept of religion as an institution is a historical construction. The process of reification is transformation and religious system and term form adjective such as spiritual, faith and belief becomes a noun, a religion. ${ }^{1617}$ At its late growth vary religions were not a manifested institution consist of leaders, law, site, etc., but were an informal tradition or system that refers to belief and spirituality. This extended definition of religion delineates spirituality and belief enable to "one may find spirituality in many fields; some may find spiritual elements in very ordinary activities like singing, cooking and so on" ${ }^{18}$ Defining religion as the faith in spiritual being will shed the light on assorted stable encounter points between religion and mathematics. .

\section{Methods}

The research method used in this study is a literature review. This study

\footnotetext{
15 Bouckaert and Zsolnai, The Palgrave Handbook of Spirituality and Business.

16 Wilfred Cantwell Smith, The Meaning and End of Religion (Fortress Press, 1963).

17 Talal Asad, "Reading a Modern Classic: WC Smith's" The Meaning and End of Religion"," History of Religions 40, no. 3 (2001): 205-222.

18 Kessler, "Spirituality in Mathematics," 50.
} 
collects systematically a variety of literature related to the theme under study. Various scientific works such as books and journal articles are analyzed to reveal the formulation of the problem posed. In this study, various books relating to religion and mathematics were examined. To deepen the understanding of the relationship between religion and mathematics, various journals are also analyzed. The existing literature text is read and analyzed critically and systematically so that it can give rise to a patterned description of the proposed problem formulation.

\section{Result and Discussion}

The encounter between mathematics and religion shows a complex and multifaceted phenomenon. We could witness that mathematics and religion have many dimensions and the monolithic interpretation of them is misleading. This intricate diversity enacts the connections between them are many forms. It cannot be denied that they have opposite sides. But on the other hand, they merge into a single form that is difficult to sort out. Here, it will be discussed several intersection points where religion and mathematics possibly interact. The encounter between religion and mathematics undergoes at five dimensions, those are described as follows:

\subsection{Ontological Dimension}

Mathematics is a pursuit of a consistent pattern and an idealistic form of reality. Religious activity, a search of ultimate truth and the nature of reality, shares certain commonness with mathematics activities. Hence, in the ontological dimension mathematics resembles religion, especially in terms of an inquiry of ultimate reality. This encounter point is detected because there is something of a spiritual nature inherent in mathematics. ${ }^{19}$ Based on the comparable definition and natural characteristic of them, it is possible to denounce that they intersect each other.

In the history of mathematics, it has been noted that mathematics has both quantitative and qualitative characteristics as prevailing in the Pythagorean tradition of number and spirituality. Unfortunately, for the last several hundred years; the insight of qualitative aspect of mathematics has gradually perished. ${ }^{20}$ The elderly version of mathematics has no vivid borders separating it from other

\footnotetext{
19 Klaus G. Witz, Spiritual Aspirations Connected with Mathematics: The Experience of American University Students (Edwin Mellen Press Lewiston^ eME ME, 2007), 326.

20 Voss, "Mathematics and Theology," 33.
} 
disciplines and traditions including religiosity.

Mathematics has an unambiguous and vivid symbol that makes it considered a reliable and universal language. Hence, to some extent, mathematics leads us through science and brings us to questions about a greater reality called metaphysical reality, which we usually approach in the context of philosophy and religion. ${ }^{21}$ This prominence characteristic of mathematics, leading to ultimate reality, has driven its activities comparable to philosophy, theology, and religion.

\subsection{Epistemological Dimension}

It is obvious that the way of knowing between mathematics and religion has a distinctive difference, but it does not mean that they have no identical characteristics. The characteristic of logic, consistency, and rationality are attached in mathematics. Meanwhile, the religious system of knowing is dominated by belief, intuitive knowledge, and doctrine. Nevertheless, mathematics and religion are not binary and disjunctive. There are certain characteristics of religion that are adopted by mathematics, and vice versa. To a certain degree, religion vividly uses logic and rationality in its epistemological system. Such as determining certain religious law and deriving ethical conduct from certain tenet doctrines requires a logical process. On the other hand, mathematics has theorem and axiom that are accepted without any verification. Even though this is quite different in math and science but it indicates that there is unquestioned acceptance for certain statements in mathematics that is identical to religion. This similarity cannot be concluded that mathematics is religion, but at least this similarity reveals an opportunity for every person to experience both religiosity and mathematics process in coincide moment.

The intersection between religion and mathematics emerges when there are similar activities between them. The mathematical method requires the idealization of reality and turns them into symbols and formulas to attain the order and harmony of nature. This process is similar to the process of theologians in their contemplation about reality and nature. Therefore, mathematical epistemology is a search for harmony and beauty of the universe as Platonism believed and did in their mathematical activities. ${ }^{22}$ Mathematical epistemology provides an inner vision of reality. And, this qualification is a intersect spot for religious and mathematical activities.

21 Leach, Mathematics and Religion.
22 Kessler, "Spirituality in Mathematics." 


\subsection{Teleological Dimension}

Metaphysics and religion try to answer why the world is the way it is. ${ }^{23}$ Religion, especially theology has a predominant purpose to leads the adherent to God. Kessler stated that mathematicians encounter spirituality while doing the mathematics process because mathematics is understood as a spiritual path leaning to the Divine..$^{24}$ Even though it is obvious, I will not say that the mathematical process is one of the parts of religion. It is correct that the mathematical activities may lead to a spiritual journey, but it does not guarantee that mathematics will reveal spirituality and emerge spiritual experience. The intersection point between religion and mathematics is still detected, but mingling both is misleading. So, what we can learn from this phenomenon is that the purpose of mathematics relates to religion or theology namely the search for a greater reality. ${ }^{25}$

The encounter point between mathematic and religiosity is in the teleological aspect or the purpose of them. For Plato, mathematical studies were a preparation for the contemplation of the divine principles, for the Pythagoreans, mathematics itself was the study of God immanent in His creation. ${ }^{26}$ The ancient mathematical tradition regards its purpose to reach spirituality and divinity. They consider that God manifests in the universe as natural law and the order of the cosmos. Hence, to grasp and comprehend God's behavior, the human should practice their contemplative mind by doing mathematical activities that are able to show the divine pattern of the universe.

As a knowledge system to grasp the ultimate truth, theology in religious tradition has resemblance purpose to mathematics'. The language of mathematics holds a privileged status in human affairs. It is a kind of public language that allows us, as best we can, to try to achieve objectivity and certainty. ${ }^{27}$ In almost all religions, god is belied as an ultimate truth that is perused by obeying religious conducts and laws. The purpose of both mathematics and religion is similar, namely the ultimate truth, even though they may perceive the ultimate truth differently and they pursued it in an inverse process. Regardless of their perception and the way to obtain it, in this point, mathematics and religion share commonality in the term of their purpose or teleology.

${ }^{23}$ Leach, Mathematics and Religion, 129.

${ }^{24}$ Kessler, "Spirituality in Mathematics," 51.

${ }^{25}$ Leach, Mathematics and Religion.

${ }^{26}$ Kessler, "Spirituality in Mathematics," 51.

${ }^{27}$ Leach, Mathematics and Religion, 129. 


\subsection{Theoretical Dimension}

In the Classic Greek tradition (such as Pythagoras and Plato), spirituality and mathematics were close to each other. ${ }^{28}$ But, nowadays the modernism and secularism proliferate in the body of mathematics. As consequence, modern mathematics has been distilled from its spiritual aspect. Mathematics and religious tradition has taken dissimilar path and constituted each distinctive discipline. This disengagement may not lead them to absolute separation. They still have the opportunity for encountering each other in this modernized world.

Religions for hundred years have presented various narrations and perceptions about the meaning of the world. Several religious concepts such as creation, The almighty God, angels, demons, heaven and hell explain how the universe works. Historically, after the renaissance and scientific revolutions, religious explanation toward the universe is gradually abandoned and replaced by scientific explanation. Nevertheless, when the new age of religions began to emerge, modern scientific theories and mathematics began to be interpreted as metaphors supporting religious concepts and doctrines. Various mathematical concepts that are comparable to religious concepts are utilized as a metaphor to explain religious teaching and conception. For instance, Hofstadter draws analogies between Godel's incompleteness theorem and our human inability to determine our level of saneness, our inability to truly "know themself," and even our spiritual need to come to grips with our mortality. ${ }^{29}$ In this case, Godel's incompleteness theorem is not merely understood as a mathematical theory, furthermore, it is interpreted as a metaphor or analogy to explaining certain religious concepts that have comparable characteristics with it. As Voss explained, "when we metaphorically extend the Heisenberg uncertainty principle to the realm of the spiritual, we entertain the possibility of an Uncertain or Ambiguous God or, at the very least, of an ambiguous existence." 30 The theoretical aspects of mathematics that are compatible with religious conception and can be metaphorically interpreted are used for explaining or firming religious concepts. This religious interpretation of the mathematical theory is an encounter point between religion and mathematics.

\footnotetext{
28 Kessler, "Spirituality in Mathematics," 52.

29 Voss, "Mathematics and Theology," 45.

30 Voss, 37.
} 


\subsection{Application and Practical Domain}

The encounter of religion and mathematics also takes place in the external domain name in the application and the person who uses them. When we talk about the internal domain, as delineated previous section of this article, we refer to certain aspects that exist inside of mathematics and religion such as theory, epistemology, teleology, and ontology. On the other side, the external domain is an outside aspect of mathematics and religion. It does not refer to certain mathematics theories or several religious doctrines, but something outside of them. The social aspects of mathematics, application of mathematics, adherents of religion, mathematics pedagogy are various examples of the external domains which have the potential for encounter point.

Various studies on mathematics education also reveal how it relates to religion, beliefs, and values. Various activities that are undertaken to manage mathematics class originate from religious values. Consistency, justice, and togetherness are religious values that appear on the pedagogical side of mathematics. This encounter may not directly converge religion and mathematics, but it is more the connection of both proxies in the practical side.

\section{Conclusion}

This study reveals that there are several points where mathematics and religion interact. Sometimes, they are regarded as being opposing, different, and equivalent. The encounter between them exists in ontological, epistemological, teleological, theoretical, and application dimensions. This study more focused on similarities to reveal the connection between religion and mathematics. This does not rule out the possibility to reveal the opposite side of them to reveal their connections and interactions. Two different things are not always in conflict. It is hoped that this can be done in further studies.

\section{Reference}

Asad, Talal. "Reading a Modern Classic: WC Smith'”"The Meaning and End of Religion”." History of Religions 40, no. 3 (2001): 205-222.

Bouckaert, L., and L. Zsolnai. The Palgrave Handbook of Spirituality and Business. Springer, 2011.

Boyer, Carl B., and Uta C. Merzbach. A History of Mathematics. John Wiley \& Sons, 2011. 
Devlin, Keith. Mathematics: The Science of Patterns: The Search for Order in Life, Mind and the Universe. Henry Holt and Company, 1996.

Gregory, Andrew. "The Pythagoreans: Number and Numerology." Mathematicians and Their Gods: Interactions between Mathematics and Religious Beliefs. Oxford, UK, 2015.

Harari, Yuval Noah. Sapiens: A Brief History of Humankind. Vintage, 2019.

Horky, Philip Sidney. Plato and Pythagoreanism. Oxford University Press, 2013.

Kessler, Volker. "Spirituality in Mathematics." Journal for the Study of Spirituality 9, no. 1 (2019): 49-61.

Koetsier, Teun, and Luc Bergmans. Mathematics and the Divine: A Historical Study. Elsevier, 2004.

Leach, Javier. Mathematics and Religion: Our Languages of Sign and Symbol. Templeton Press, 2010.

Smith, Wilfred Cantwell. The Meaning and End of Religion. Fortress Press, 1963.

Stenmark, Mikael. How to Relate Science and Religion: A Multidimensional Model. Wm. B. Eerdmans Publishing, 2004.

Voss, Sarah. "Mathematics and Theology: A Stroll through the Garden of Mathaphors." Theology and Science 4, no. 1 (January 2006): 33-49. https:// doi.org/10.1080/14746700500501841.

Witz, Klaus G. Spiritual Aspirations Connected with Mathematics: The Experience of American University Students. Edwin Mellen Press Lewiston^ eME ME, 2007. 
